American Journal of Pharmaceutical Education 2009; 73 (3) Article S1.

\title{
AACP SUPPLEMENT
}

\section{Report of the Journal Editor}

\author{
Joseph T. DiPiro, PharmD \\ Editor, American Journal of Pharmaceutical Education
}

May 1, 2009

This report is a compilation of activity and statistics for the American Journal of Pharmaceutical Education for 2008 (Volume 72). The Journal was published in electronic format at www.ajpe.org. A print edition of the full volume was also produced and sent to all AACP member institutions and paid subscribers. Six issues were published in 2008 plus supplementary material. In October 2004 the AACP Board approved plans for the Journal to expand publication by publishing 8 issues in 2009 and 10 issues in 2010.

In 2008 there were over one-half million "unique visitors" to the Journal web site, averaging approximately 40,000 per month, a $100 \%$ increase from the previous year. After the United States, the countries with the most Journal readers were Brazil, India, China, Venezuela, and Turkey. One hundred and thirteen peer-reviewed manuscripts were published in Volume 72 (a 25\% increase from the previous year) along with a large number of Viewpoints, Addresses, Reports, Statements, Book Reviews, and other material (Table 1). Two hundred thirty one manuscripts were submitted to the Journal,

Table 1. Journal Activity in 2008 (Volume 72)

\begin{tabular}{lr}
\hline Papers submitted & 231 \\
Manuscript acceptance rate, \% & 46 \\
Manuscripts published & \\
Research Articles & 38 \\
Instructional Design and Assessment & 25 \\
Teachers' Topics & 10 \\
Innovations in Teaching & 7 \\
Special Articles & 13 \\
Reviews & 1 \\
Statements & 4 \\
Special Supplement Articles & 15 \\
Other materials published & \\
Viewpoints & 17 \\
Addresses & 4 \\
Reports and Minutes & 22 \\
\hline
\end{tabular}

similar to the previous year. Of these, $46 \%$ were accepted for publication. Over 350 individuals served as manuscript and book reviewers. Two supplements were published in 2008, one on International Pharmacy Education and the second was papers from the AACP Institute on Evaluation, Assessment, and Outcomes.

International interest in the Journal continues to grow as evidenced by the web site statistics given above. Also, we are receiving more manuscripts and publishing more manuscripts from international authors compared with previous years.

Six new Editorial Board members were appointed in 2008 for 3-year terms: Deborah Harper-Brown (IllinoisChicago), Susan Burton (Port Elizabeth, South Africa), Shobba Rani Hiremath (Bangalore, India), Laurence Kennedy (Butler), Nathaniel Rickles (Northeastern), and Nick Shaw (Queensland, Australia) Stephanie Gardner (Arkansas), William Lubawy (Kentucky), L. Douglas Ried (Florida), and Julie Szilagyi (Houston) were reappointed to the Board.

Each year the best paper published in the Journal is recognized with the Rufus A. Lyman Award. Rufus A. Lyman was the first Editor of the American Journal of Pharmaceutical Education. Papers are selected based on utility and significance to pharmacy education, originality, research methodology, and writing style. The Lyman Award Committee, which is appointed by the President and chaired by the Editor, selected the top paper. From volume 72, 17 papers were nominated for the Lyman Award and the Award winning paper was "The Economic Impact of a College of Pharmacy" by Dick Gourley, PharmD, Shelley White-Means, PhD, and Jeff Wallace, $\mathrm{PhD}$ from the University of Tennessee-Memphis.

The Editor is indebted to the Associate Editors Gayle Brazeau, Jack Fincham, and Claire Anderson, and Senior Assistant Editor Karen Shipp, Editorial Board Members, the manuscript and book reviewers, and the AACP Board of Directors and staff for their continued efforts and support. The success of the Journal is dependent on the diligent and dedicated efforts of these individuals. 